\title{
Phenolic compounds of Iris adriatica and their antimycobacterial effects
}

\author{
SANDRA OCHENSBERGER ${ }^{1}$ \\ FABIAN ALPERTH ${ }^{1}$ \\ BOŽENA MITIĆ ${ }^{2}$ \\ OLAF KUNERT ${ }^{3}$ \\ STEFANIE MAYER ${ }^{1}$ \\ MARIA FERREIRA MOURÃO ${ }^{4}$ \\ IVANA TUREK ${ }^{1}$ \\ SIMON VLAD LUCA ${ }^{5}$ \\ KRYSTYNA SKALICKA-WOŹNIAK ${ }^{6}$ \\ ŽELJAN MALES̆ $\breve{T}^{7}$ \\ DARIO HRUŠEVAR ${ }^{2}$ \\ IVAN DUKA ${ }^{7}$ \\ FRANZ BUCAR ${ }^{1^{*}}$ \\ ${ }^{1}$ University of Graz, Institute of Pharmaceutical \\ Sciences, Department of Pharmacognosy, 8010 Graz \\ Austria \\ ${ }^{2}$ University of Zagreb Faculty of Science, Department \\ of Biology (Botany), HR-10000 Zagreb, Croatia \\ ${ }^{3}$ University of Graz, Institute of Pharmaceutical \\ Sciences, Department of Pharmaceutical Chemistry \\ 8010 Graz, Austria \\ ${ }^{4}$ University of Lisbon, Faculty of Pharmacy, 1649-003 \\ Lisboa, Portugal \\ ${ }^{5}$ Department of Pharmacognosy, Grigore T. Popa \\ University of Medicine and Pharmacy Iasi, 700115 \\ Iasi, Romania \\ ${ }^{6}$ Department of Pharmacognosy with Medicinal Plant \\ Unit, Medical University of Lublin, 20-093 Lublin \\ Poland \\ ${ }^{7}$ University of Zagreb Faculty of Pharmacy and \\ Biochemistry, Department of Pharmaceutical Botany \\ HR-10000 Zagreb, Croatia
}

Accepted March 17, 2019

Published April 24, 2019
Little is known about the pharmacological activities of Iris adriatica (Iridaceae), a plant endemic to Dalmatia (Croatia). We therefore performed a bioassay-guided fractionation including highperformance counter current chromatography (HPCCC) and antibacterial tests using Mycobacterium smegmatis $\mathrm{mc}^{2} 155$. One obtained fraction was found to be antimycobacterially active with a MIC of $64 \mathrm{mg} \mathrm{L}^{-1}$. Furthermore, fractions were tested for resistance modulatory effects using ethidium bromide as substrate. We were able to identify the pure isoflavonic compounds irigenin and irilone and a fraction containing mainly benzophenone 2,4,6-trihydroxy-4-methoxy-benzophenone, responsible for the resistance-modulatory activity of this plant.

Keywords: Iris adriatica, Radix Iridis, phenolic compounds, Mycobacterium smegmatis, resistance modulation, ethidium bromide, MIC

Iris adriatica Trinajstić ex Mitić (Iridaceae) is a rhizomatous plant endemic to Croatia, restricted to the broader central Dalmatian region. The plant is characterized by a dwarf

\footnotetext{
* Correspondence; e-mail: franz.bucar@uni-graz.at
} 
habit and yellow or violet solitary flowers. I. adriatica is listed as one of about 350 species of the genus Iris, where it is considered as one of the smallest species in this genus $(1,2)$. I. adriatica has not been researched extensively and therefore limited data is available. Rhizomes of Iris species were traditionally used in European medicine as expectorant, stimulant, diuretic, emetic drugs and supplements in toothpowders. Also, a specialty for teething children, Rhizoma Iridis pro infantibus, is reported, which consists of long pieces of rhizomes that are chewed for pain relief (3). In Traditional Chinese Medicine, the mixture "She-gan" including Iris species is used against cough and pharyngitis (4). Furthermore, a variety of activities against cancer, inflammation, hyperlipidemia and neurodegenerative diseases are reported for various Iris species $(5,6)$. The postulated toxicity of Iris, causing diarrhea, nausea and skin irritations (7), is not documented in literature for I. adriatica. Iridin and myristic acid are mentioned as irritant substances that can be found at high concentrations in rhizomes of plants of this genus (7).

Thus far, over 30 compounds have been isolated and identified from the rhizomes of I. adriatica $(8,9)$. A detailed metabolic profiling of phenolic compounds of the rhizomes of native populations of $I$. adriatica was recently published by our group (8). Mainly phenolic compounds such as isoflavones are found in large numbers and quantities, followed by xanthones and benzophenones. Representing the most abundant substance group, germanaism B was found as the leading isoflavone. Irilone, another found isoflavone was reported to be antidiabetically active by inhibiting $\alpha$-amylase and to be of phytoestrogenic nature when used in combination with red clover $(10,11)$. Concerning xanthones, mangiferin and irisxanthone are heading the list (8). In literature, mangiferin is reported to possess analgesic, antidepressant, antidiabetic, antiinflammatory, antioxidant, antiproliferative, antiviral, diuretic and immunomodulatory properties $(12,13)$. Some isoflavones, namely, irigenin and irilone, were reported to be potent inhibitors of the cytochrome P450 $1 \mathrm{~A}$ enzyme and to be of chemopreventive nature (3). At a glance, several pharmacologically promising activities were reported for compounds found in I. adriatica, but no antibacterial data was reported for this species.

Developing resistance rates challenge health care systems and research worldwide. Due to the fact that bacteria have rapidly become resistant to antibiotics on the market, it is not surprising that the World Health Organization reports increasing numbers of resistant tuberculosis (TB) being by now the leading cause of death caused by a single infectious agent. In 2017, $82 \%$ of all resistant TB cases were of multidrug-resistant manner (14). Therefore, new strategies to combat increasing resistance rates are urgently needed. One of the approaches to limit resistance development is the application of so called efflux pump inhibitors, which are able to block the outward transport of antibiotics from cells (15). The boundless pool of plants in the world is still an insufficiently explored field for new antibacterials and efflux pump inhibitors. A continued study of Newman et al. has shown the high impact of plants as sources for new drugs (16). Therefore, exploitation of the so far unresearched plant material is of high importance to obtain new antibacterials for the fight against resistant microbes.

Antibacterial effect of Iris sp. was already detected against Escherichia coli, Pseudomonas aeruginosa, Salmonella typhi and Staphylococcus aureus (17). Interestingly, in that study it was found that Proteus vulgaris seems to be resistant to extracts of five Iris species. The reported antituberculotic activity of I. germanica leaves could not be confirmed by literature research, which only resulted in negative documentation against Mycobacterium tuberculo- 
sis (5). The aim of our study was to assess whether Iris adriatica is an antimycobacterial agent, which was facilitated by bioassay-guided fractionation. In addition to the already putative antiinflammatory, phytoestrogenic, antidiabetic and chemopreventive activities of compounds found in I. adriatica, we would like to shed light on the potential of this plant against mycobacteria.

\section{EXPERIMENTAL}

\section{Plant material and extraction}

Rhizomes of I. adriatica were collected at native sites in April 2016 (Table S1) and airdried for one month, followed by Soxhlet extraction of $261.5 \mathrm{~g}$ plant material with methanol (extraction yield $16.3 \%$ ). As plant material of endemic I. adriatica from its original habitats was not available in large amounts, in this study we also included a pure compound isolated from a commercial sample of Radix Iridis (which can include rhizomes originating from I. germanica, I. pallida or I. florentina (18), Kottas Pharma (Austria) based on the fact that this substance was also identified in I. adriatica (8).

\section{Analysis of extracts, fractions and pure compounds by UHPLC-PDA-ESI-MS}

Analysis was carried out according to a method recently published by our group (8). In short, a Dionex Ultimate 3000 RS LC system coupled to a LTQ XL linear ion-trap mass spectrometer equipped with an ESI ion source (all components Thermo Scientific) and a Zorbax SB-C18 Rapid Resolution HD column, $100 \times 2.1 \mathrm{~mm}, 1.8 \mu \mathrm{m}$ particle size (Agilent), were used. Elution with $0.1 \%$ formic acid in water (A) and gradient grade acetonitrile (B) started with $8 \% \mathrm{~B}$, increasing to $45 \%$ B 0-9 min; $9-13 \min 45 \%$ B to $100 \%$ B; $13-15$ min $100 \% \mathrm{~B} ; 15-15.5 \mathrm{~min} 100 \% \mathrm{~B}$ to $8 \% \mathrm{~B}$, equilibrating for $8 \mathrm{~min}$ at a flow rate of $0.39 \mathrm{~mL}$ $\mathrm{min}^{-1}$. Column temperature was set to $35^{\circ} \mathrm{C}$, injection volume was kept at $2 \mu \mathrm{L}$. PDA detection was performed in the wavelength range of 190 to $500 \mathrm{~nm}$. Mass spectra were recorded in negative and positive ion modes in the $\mathrm{m} / \mathrm{z}$ range of 50 to $2000 \mathrm{amu}$. (source voltage $3.5 \mathrm{kV}$ (ESI pos), $5.0 \mathrm{kV}$ (ESI neg); capillary temperature $300^{\circ} \mathrm{C}$; source temperature $350^{\circ} \mathrm{C}$; sheath gas flow 65 arb (arbitrary units), auxiliary gas flow $15 \mathrm{arb})$.

\section{Fractionation and isolation of compounds from I. adriatica}

Fractionation was carried out with vacuum column chromatography (CC) using silica gel 60 (Normasil 60; 0.040-0.063 $\mu \mathrm{m}$ VWR Chemicals) and solvents following the gradient: n-hexane/EtAc 80:20, n-hexane/EtAc 50:50, n-hexane/EtAc 0:100, methanol/EtAc 20:80, methanol/EtAc 35:65, methanol/EtAc 50:50, methanol/EtAc 100:0 and methanol/water 90:10 (19). $20.2 \mathrm{~g}$ of crude methanolic extract was applied to $200 \mathrm{~g}$ of silica gel (resulting in 31 fractions (F1-31). Obtained fractions were combined to 10 subfractions according to their thin layer chromatographic profile (TLC plates silica gel $60 \mathrm{~F}_{254}$, Merck, mobile phase toluene/ethyl formate/formic acid 5:4:1). Irilone was purified from F9-10 (representing subfraction 2, eluted with $n$-hexane/EtAc 0:100) by subsequent high-performance countercurrent chromatography (HPCCC) fractionation. Spectrum HPCCC (Dynamic Extractions Co. Ltd., Slough, Berkshire, UK) was equipped with analytical $(22 \mathrm{~mL}, 0.8 \mathrm{~mm}$ i.d., $1 \mathrm{~mL}$ sample loop) and semipreparative (137 mL, $1.6 \mathrm{~mm}$ i.d., $6 \mathrm{~mL}$ sample loop) coils. The following 
parameters were used: semi-preparative coil; rotation speed $1600 \mathrm{rpm}$, flow-rate $6 \mathrm{~mL}$ $\mathrm{min}^{-1}$; stationary phase - upper phase (reversed-phase mode or head-to-tail mode); temperature $30{ }^{\circ} \mathrm{C}$; detection wavelength $260 \mathrm{~nm}$. For the HPCCC fractionation of F9-10 (100 $\mathrm{mg}$ ), a two-phase solvent system composed of $n$-hexane/EtAc/2-propanol/methanol/water (5:6:2:3.5:6, $V / V)$ was used to get pure irilone $(6.6 \mathrm{mg})$ in $38-42 \mathrm{~min}$. Additional HPCCC fractionation of F9-10 (60 mg) with $n$-hexane/EtAc-2-propanol/methanol/water (5:6:3:3.5:6, $V / V)$ led to F-B (5.9 mg), a fraction rich in 2,4,6-trihydroxy-4-methoxy-benzophenone (ca. $90 \%$ ) as verified by LC-PDA-ESI-MS analysis (8), in 25-26 min.

Fractionation of F9-10 (100 mg) was also carried out by open column chromatography using Sephadex LH-20 as stationary phase (column $2 \times 45 \mathrm{~cm}$ ), while EtAc and methanol $(9: 1, V / V)$ served as eluents. Obtained fractions were merged to 6 fractions, from which sub-fractions were collected using semipreparative reversed phase $(\mathrm{C} 18)$ high performance liquid chromatography. Semipreparative HPLC was carried out on a Shimadzu system (CBM-20A controller, LC-20AT solvent delivery module, SIL-10AF autosampler, CTO-20AC column oven, SPD-M20A diode array detector, FRC-10A fraction collector) using a Luna C18(2), $250 \times 10 \mathrm{~mm}, 10 \mu \mathrm{m}$ column (Phenomenex). One fraction, designated as F-IT, was obtained by elution with water:methanol (45:55) with a flow rate of $4 \mathrm{ml} \mathrm{min} \mathrm{m}^{-1}$ between 16 and 17.7 min by structure elucidation using NMR (see Table S2); it was found to be a mixture of iristectorigenin A (major amount) and irigenin to a smaller extent (ratio ca. 80:20). This fraction was also tested against mycobacteria in order to draw conclusions on structure-activity relationships.

\section{Fractionation and isolation of compounds from Radix Iridis}

In UHPLC-PDA-MS analysis, it became obvious that irigenin was present in much larger amounts in a commercial sample of Radix Iridis (see Fig. S1); hence, this material was used for isolation of this isoflavonoid. An ethanolic Soxhlet extract of Radix Iridis was prepared by extracting $300 \mathrm{~g}$ of powdered plant material with ethanol (96\%) for $4 \mathrm{~h}$ to yield $31.1 \mathrm{~g}$ extract (10.4\% extraction yield). After pre-fractionation by vacuum CC on silica (Normasil 60; 0.040-0.063 $\mu \mathrm{m}$ VWR Chemicals) with a gradient as used for I. adriatica (see above), HPCCC fractionation of fraction C (100 mg, eluted with EtAc from the silica column) with $n$-hexane/EtAc/2-propanol/methanol/ (5:6:2:4.5:6, V/V) yielded pure irigenin (13.1 mg) in 16-19 min. This substance was also identified in I. adriatica and therefore subjected to antimycobacterial testing in order to gain an insight into the activities exerted by pure compounds.

Structures of isolated isoflavonoids were confirmed by NMR analysis $\left({ }^{1} \mathrm{H},{ }^{13} \mathrm{C}, \mathrm{HMBC}\right.$, HSQC); data are presented in Table S2.

\section{Antimycobacterial assays}

Extracts, fractions and pure compounds were tested at an established minimum inhibitory concentration (MIC) and modulation factor $(M F)$ assay against the strain Mycobacterium smegmatis $m c^{2} 155$ (ATCC 700084) (20). MIC assay was carried out with the crude extract at the initial concentration of $512 \mathrm{mg} \mathrm{L}^{-1}$, whereas fractions were tested at $256 \mathrm{mg} \mathrm{L}^{-1}$ and pure compounds at $128 \mathrm{mg} \mathrm{L}^{-1}$. Testing agents were diluted in dimethyl sulfoxide prior to testing and added into 96-well plates in duplicate, serially diluted with Mueller Hinton Broth medium and incubated with a $5 \times 10^{5} \mathrm{cfu} \mathrm{mL}^{-1}$ bacterial inoculum for 72 hours at $37^{\circ} \mathrm{C}$ 
$(n=2)$. Isoniazid was added as a control substance to each plate for intra-plate monitoring and both sterile and growth control were performed on each plate. The same conditions were applied for the MF assay, whereby the testing concentration was set to $1 / 2$ of the determined MIC. In our model, we standardly used ethidium bromide (EtBr) in order to reveal the resistance modifying effects based on efflux pump inhibition, since EtBr has been shown to be the substrate of many efflux pumps. The modulation factor clarifies the MIC reduction of the antibiotic in the presence of a modulator. The higher the MF, the lower is the amount of substance needed to exert the same antibacterial effect. All plates, independently of the assay, were evaluated with a colorimetric assay using MTT after 30 min of additional incubation.

\section{RESULTS AND DISCUSSION}

Analysis of the crude extracts, fractions and pure compounds obtained after isolation procedures was done by UHPLC-PDA-ESI-MSn as previously reported (8). Identification

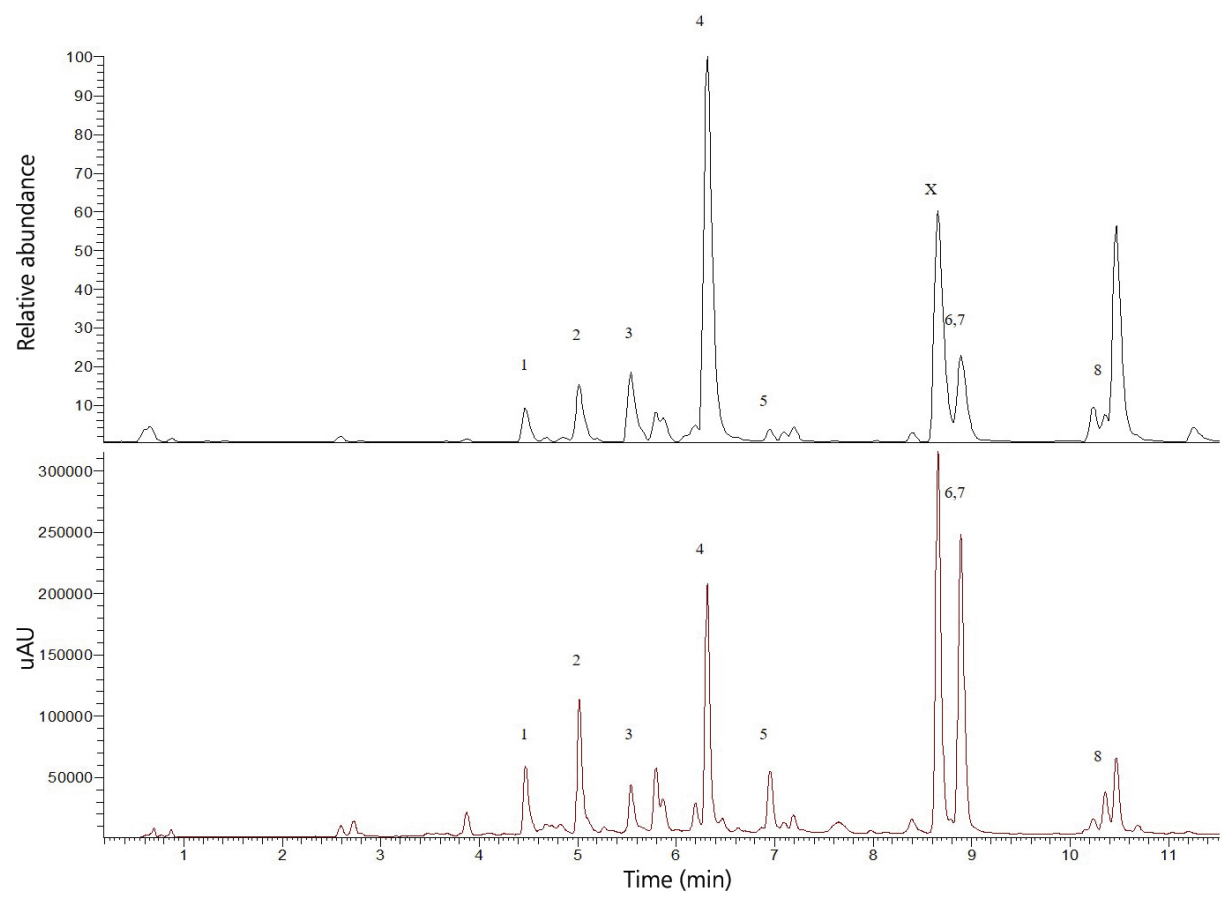

Fig. 1. UHPLC-PDA-ESI-MS analysis of the methanolic extract of Iris adriatica rhizomes. Base peak chromatogram ESI positive mode (top) and UV chromatogram at $290 \mathrm{~nm}$ (bottom). Compounds marked with numbers were found in fractions or isolated as pure compounds for antimycobacterial testing. $1=$ irisxanthone (in mixture with iristectorigenin A-O-trihexoside); $2=$ iristectorigenin A-7-O-[ $\beta$-Dglucopyranosyl-( $1 \rightarrow 6)-\beta$-D-glucopyranoside], in mixture with other isoflavonoids; $3=$ germanaism $\mathrm{E}$; 4 = germanaism B; $5=2,4,6$-trihydroxy-4-methoxy-benzophenone; 6 = iristectorigenin A; 7 = irigenin; 8 = irilone; $X=$ mixture of isoflavones $\left(M_{\mathrm{r}}=312\right.$ (irisolone), 330, 360). 
Table I. Antimycobacterial results of Iris adriatica extract, fractions and pure compounds against Mycobacterium smegmatis

\begin{tabular}{ccc}
\hline Fraction/Substance & MIC $\mathrm{mg} \mathrm{L}^{-1}\left(\mu \mathrm{mol} \mathrm{L}^{-1}\right)$ & $\mathrm{MF}_{\mathrm{EtBr}}$ \\
\hline Crude extract $(\mathrm{MeOH})$ & 512 & 4 \\
F1-3 & $>256$ & 1 \\
F4-6 & $>256$ & 1 \\
F7-8 & $>256$ & 1 \\
F9-10 & 64 & 2 \\
F11-14 & 256 & 2 \\
F15-18 & $>256$ & 2 \\
F19-20 & $>256$ & 1 \\
F21-24 & $>256$ & 1 \\
F25-27 & $>256$ & 0.5 \\
F28-31 & $>256$ & 0.5 \\
F-B & $>256(983.71)$ & 4 \\
F-IT & $>256(775.08)$ & 2 \\
Irigenin & $128(355.25)$ & 4 \\
Irilone & $>256(858.34)$ & 4 \\
Isoniazid & $4-8(29.17-58.33)$ & - \\
EtBr & $8(20.29)$ & - \\
\hline
\end{tabular}

EtBr - ethidium bromide, F-B - fraction mainly containing 2,4,6-trihydroxy-4-methoxy-benzophenone, F-IT - fraction largely containing iristectorigenin $\mathrm{A}$ and to a smaller extent irigenin, $\mathrm{MeOH}$ - methanol, $\mathrm{MF}-$ modulation factor, MIC - minimum inhibitory concentration, $n=2$.

was deduced from mass spectral fragments as well as UV data, in case of isolated compounds finally confirmed by two dimensional NMR analysis. Figure 1 shows a representative ESI-MS base peak chromatogram (positive mode) and a UV chromatogram $(290 \mathrm{~nm})$ of the methanolic extract of I. adriatica rhizomes with the compounds relevant for our study on antimycobacterial activity.

Testing of the methanolic crude extract revealed no antimycobacterial effect against M. smegmatis. The modulation factor assay indicated a promising MF of 4 which means a 4 -fold reduction of MIC value of the testing agent (in our case EtBr) when used in combination with the modulator (plant extract/pure compound). This extract was therefore further separated to possibly assign a pure compound of particular antibacterial value. Except for fraction F9-10 with a MIC of $64 \mathrm{mg} \mathrm{L}^{-1}$, no antimycobacterial effect was documented for I. adriatica fractions. Also, pure compounds were not able to inhibit mycobacterial growth sufficiently when tested in the MIC assay. MF testing revealed F9-10, F11-14 and F15-18 as moderately active, resulting in a MF of 2. Regarding pure compounds, the fraction F-B (2,4,6-trihydroxy-4-methoxy-benzophenone), irigenin and irilone were found to be responsible for the resistance-modulatory activity of I. adriatica (Table I). Hence, the resis- 
tance modulatory effect of the crude methanolic extract of I. adriatica cannot be referred to a single compound but to the concerted action of at least three compounds; further interactions with other extract components cannot be excluded. By comparing values of F-IT and irigenin it can be seen that irigenin is the most active component owing to the lower MF determined in the mixture with iristectorigenin A. For irigenin, cytotoxicity testing was performed using A549 and $\mathrm{CaCo} 2$ cells resulting in values of $22.57 \mu \mathrm{M}$ and $39.88 \mu \mathrm{M}$, respectively (21). Ehrlich's ascites carcinoma cells were incubated with irilone and the compound was able to show cytotoxicity of $47.7 \mu \mathrm{M}$ for MTT experiments (22). Fig. 2 shows the corresponding structural formulas of the essential pure compounds that were found to be active in I. adriatica, revealing diverse structural features, i.e., a highly methoxylated isoflavone (irigenin), an isoflavone bearing a methylene dioxy residue (irilone) and a methoxylated benzophenone; hence, no clear conclusions on structure activity relationships can be drawn. Using LC-PDA-ESI-MS analysis (8), the following compounds were identified in fractions F19-20 and F21-24: germanaism B and irisxanthone (both fractions), iristectorigenin A-7-O-[ $\beta$-D-glucopyranosyl-(1 $\rightarrow 6)-\beta$-D-glucopyranoside] and germanaism $\mathrm{E}$ (only in F21-24). These compounds were not able to elicit any antimycobacterial or resistance-modulatory activity. These results point to the conclusion that the glycoside of iristectorigenin A (F21-24, MF of 1) is of less resistance-modulatory potency compared to aglycone (F-IT).

The results of irigenin and irilone are in line with those of biochanin A (genistein- 4 'methyl ether), for which efflux-modulatory activity against $M$. smegmatis was previously reported (20). Pure compounds of I. adriatica are therefore promising candidates for subsequent studies.<smiles>COc1cc(-c2coc3cc(O)c(OC)c(O)c3c2=O)cc(O)c1OC</smiles>

Irigenin<smiles>O=c1c(-c2ccc(O)cc2)coc2cc3c(c(O)c12)OCO3</smiles>

Irilone<smiles>COc1cc(O)c(C(=O)c2ccc(O)cc2)c(O)c1</smiles>

\section{2,4,6-trihydroxy-4-methoxy-benzophenone}

Fig. 2. Chemical structures of resistance-modulatory active compounds found in Iris adriatica tested against Mycobacterium smegmatis. 


\section{CONCLUSIONS}

We were able to identify two isoflavones and one benzophenone with resistance-modulatory activity in I. adriatica and thus provide the first evidence of this plant being an antimycobacterial agent against fast-growing mycobacteria such as Mycobacterium smegmatis $\mathrm{mc}^{2}$ 155. A follow-up study would be of interest to identify the antibacterial agent in F9-10, which is still unknown. In case of restricted availability of plant material from endemic Iris species, related commercial sources of other Iris species can be employed for extraction and isolation of pure compounds. HPCCC seems to be an excellent tool for this purpose, providing pure target compounds in sufficient amounts to further test them for their efflux pump-inhibitory potential, which in turn could be helpful as adjuvants in the therapy against resistant bacteria.

Acronyms, abbreviations, symbols. - EtAc - ethyl acetate, EtBr - ethidium bromide, $\mathrm{MeOH}$ - methanol, MF - modulation factor, MIC - minimum inhibitory concentration, MTT - thiazolyl blue tetrazolium bromide, TB - tuberculosis.

Acknowledgements. - The work was supported by the project Scientific \& Technological Cooperation with Poland 2017-2019, Project No. PL 04/2017, financed by The Centre for International Cooperation \& Mobility (ICM) of the Austrian Agency for International Cooperation in Education and Research (OeAD-GmbH) and the Polish Ministry of Science and Higher Education. The authors thank anonymous reviewers, whose suggestions have improved the manuscript.

\section{REFERENCES}

1. B. Mitić, Iris adriatica (Iridaceae), a new species from Dalmatia (Croatia), Phyton 42 (2002) 305-314.

2. The Plant List. Version 1.1 (2013); http://www.theplantlist.org; last access date January 23, 2019

3. E. Wollenweber, J. F. Stevens, K. Klimo, J. Knauft, N. Frank and C. Gerhauser, Cancer chemopreventive in vitro activities of isoflavones isolated from Iris germanica, Planta Med. 69 (2003) 15-20; https:// doi.org/10.1055/s-2003-37030

4. G.-Y. Xie, Y. Zhu, P. Shu, X.-Y. Qin, G. Wu, Q. Wang and M.-J. Qin, Phenolic metabolite profiles and antioxidants assay of three Iridaceae medicinal plants for traditional Chinese medicine "She-gan" by on-line HPLC-DAD coupled with chemiluminescence (CL) and ESI-Q-TOF-MS/MS, J. Pharmaceut. Biomed. 98 (2014) 40-51. https://doi.org/10.1016/j.jpba.2014.05.008

5. S. H. Wani, B. A. Padder, T. Mokhdomi, J. I. Mir, H. A. Bhat, Q. P. Hassan and R. A. Qadri, Antiproliferative activity of methanolic extracts of different Iris plant species against A549 and Caco-2 cell lines, J. Pharmacogn. Phytochem. 6 (2017) 1034-1037.

6. F. Conforti, D. Rigano, F. Menichini, M. R. Loizzo and F. Senatore, Protection against neurodegenerative diseases of Iris pseudopumila extracts and their constituents, Fitoterapia 80 (2009) 62-67; https:// doi.org/10.1016/j.fitote.2008.10.005

7. D. G. Spoerke Jr. and S. C. Smolinske, Toxicity of Houseplants, $1^{\text {st }}$ ed., CRC Press, Boca Raton 1990.

8. F. Alperth, B. Mitić, S. Mayer, Ž. Maleš, O. Kunert, D. Hruševar and F. Bucar, Metabolic profiling of rhizomes of native populations of the strictly endemic Croatian species Iris adriatica, Plant Biosyst. 153 (2019) 317-324; https://doi.org/10.1080/11263504.2018.1478906

9. D. Bukvički, M. Novaković, N. Ab Ghani, P. D. Marin and Y. Asakawa, Secondary metabolites from endemic species Iris adriatica Trinajstić ex Mitić (Iridaceae), Nat. Prod. Res. 32 (2018) 1849-1852; https:// doi.org/10.1080/14786419.2017.1402309

10. S. R. M. Ibrahim, G. A. Mohamed, M. F. Zayed and S. A. Ross, 8-Hydroxyirilone 5-methyl ether and 8-hydroxyirilone, new antioxidant and $\alpha$-amylase inhibitors isoflavonoids from Iris germanica rhizomes, Bioorg. Chem. 70 (2017) 192-198; https://doi.org/10.1016/j.bioorg.2016.12.010 
11. S. Lutter, K. Schmalbach, H. L. Esch and L. Lehmann, The isoflavone irilone contributes to the estrogenic potential of dietary supplements containing red clover, Arch. Toxicol. 88 (2014) 309-321; https://doi.org/10.1007/s00204-013-1114-5

12. Jyotshna, P. Khare and K. Shanker, Mangiferin: A review of sources and interventions for biological activities, BioFactors, 42 (2016) 504-514; https://doi.org/10.1002/biof.1308

13. C. Cao, M. Su and F. Zhou, Mangiferin inhibits hippocampal NLRP3 inflammasome and exerts antidepressant effects in a chronic mild stress mice model, Behav. Pharmacol. 28 (2017) 356-364; https://doi.org/10.1097/FBP.0000000000000305

14. World Health Organization, Editor, Global Tuberculosis Report 2018, ISBN: 978-92-4-156564-6.

15. L. Fernandez and R. E. W. Hancock, Adaptive and mutational resistance: Role of porins and efflux pumps in drug resistance, Clin. Microbiol. Rev. 25 (2012) 661-681; https://doi.org/10.1128/CMR.0004312

16. D. J. Newman and G. M. Cragg, Natural products as sources of new drugs from 1981 to 2014, J. Nat. Prod. 79 (2016) 629-661; https://doi.org/10.1021/acs.jnatprod.5b01055

17. S. H. Wani, A. Amin, M. A. Rather, J. A. Parray, Q. Parvaiz and R. A. Qadri, Antibacterial and phytochemical screening of different extracts of five Iris species growing in Kashmir, J. Pharm. Res. 5 (2012) 3376-3378.

18. F.-C. Czygan, D. Frohne, K. Hiller, C. Holtzel and A. Nagell, Herbal drugs and phytopharmaceuticals - A Handbook for Pratice on a Scientific Basis (Eds. M. Wichtl), $3^{\text {rd }}$ ed., Medpharm - Scientific Publishers, Stuttgart 2004, pp. 312-314.

19. F. Alperth, Phytochemische und mikrobiologische Untersuchungen an Iris adriatica, Diploma thesis, Faculty of Natural Sciences, University of Graz, 2017.

20. D. Lechner, S. Gibbons and F. Bucar, Plant phenolic compounds as ethidium bromide efflux inhibitors in Mycobacterium smegmatis, J. Antimirob. Chemoth. 62 (2008) 345-348; https://doi.org/10.1093/jac/ $\mathrm{dkn} 178$

21. S. H. Wani, S. A. Lone, M. F. Mustafa, J. I. Mir, R. A. Qadri and Q. P. Hassan, Evaluation of prominent isoflavonoids of iris plant as futuristic cancer drug components, Int. J. Botany Stud. 2 (2017) 129-134.

22. G-Y. Xie, X-Y. Qin, R. Lui, Q. Wang, B-B. Lin, G-K. Wang, G-K. Xu, R. Wen and M-J. Qin, New isoflavones with cytotoxic activity from the rhizomes of Iris germanica L., Nat. Prod. Res. 27 (2013) 2173-2177; https://doi.org/10.1080/14786419.2013.796468 